\title{
A VIOLÊNCIA NA EXPERIÊNCIA DE MULHERES IDOSAS NOS CENTROS DE REFERÊNCIAS DA ASSISTÊNCIA SOCIAL
}

\author{
Violence in the Experience of elderly women In Social Assistance Reference \\ Centers
}

\author{
Maria Helena Santana Cruz (iD) \\ Doutorado em Educação (UFBA) \\ Universidade Federal de Sergipe, \\ São Cristóvão/SE, Brasil \\ helenacruz@uol.com.br \\ Thtps://orcid.org/0000-0002-7794-278X \\ Vera Núbia Santos \\ Doutorado em Serviço Social (PUC/SP) \\ Universidade Federal de Sergipe, \\ São Cristóvão/SE, Brasil \\ venus se@uol.com.br \\ https://orcid.org/0000-0002-9040-7140
}

A lista completa com informações dos autores está no final do artigo

\begin{abstract}
RESUMO
A violência contra pessoas idosas é um fenômeno dentro do atual processo de envelhecimento, ocorre de diferentes formas, e, por isso mesmo, sua identificação torna-se difícil dependendo do contexto cultural em que esteja inserida. $\mathrm{O}$ assunto que move o presente artigo reside em tornar visíveis as lógicas e motivações presentes na violência de gênero praticadas contra mulheres idosas inseridas nos centros de referência da assistência social (CRAS) em Aracaju. A pesquisa de natureza qualitativa teve seu desenvolvimento mediante a parceria entre o Núcleo de Estudos e Pesquisas Interdisciplinares sobre a Mulher e Relações de Gênero (NEPIMG) e o Conselho Municipal dos direitos da Mulher (CMDM). Diferentes fontes documentais e empíricas subsidiaram os resultados, priorizando-se sessões de grupo focal com as idosas, visando a contribuir para a avaliação de políticas e programas relacionados ao atendimento de pessoas idosas. Os tipos de violência doméstica contra idosos mais evidentes são a psicológica, a física e a patrimonial. Os cuidados com a saúde, medo da perda do convívio familiar, entre outros aspectos, contribuem para inibir denúncias de episódios de violência doméstica. $\mathrm{O}$ arcabouço normativo registra que os cuidados com os idosos são de responsabilidade da família, da sociedade e do Estado, o que sugere atentar para a centralidade da família, tendo o Estado como apoio.
\end{abstract}

PALAVRAS-CHAVE: Violência. Gênero. Mulheres Idosas. Centros de Referência da Assistência Social. Direitos.

\begin{abstract}
Violence against the elderly is a phenomenon within the current aging process, occurs in different ways, and, therefore, its identification becomes difficult depending on the cultural context in which it is inserted. The subject that moves this article is to make visible the logics and motivations present in gender violence practiced against elderly women inserted in the reference centers of social assistance (CRAS) in Aracaju. Qualitative research was developed through the partnership between its development through the partnership between the Center for Interdisciplinary Studies and Research on Women and Gender Relations (NEPIMG) and the Municipal Council for Women's Rights (CMDM). Different documentary and empirical sources supported the results, prioritizing focus group sessions with the elderly, aiming to contribute to the evaluation of policies and programs related to the care of elderly people. The most evident types of domestic violence against the elderly are psychological, physical and patrimonial. Health care, fear of losing family life, among other aspects, contribute to inhibiting reports of episodes of domestic violence. The normative framework shows that care for the elderly is the responsibility of the family, society and the State, which suggests paying attention to the centrality of the family, with the State as support.
\end{abstract}

KEYWORDS: Violence. Gender. Elderly Women. Social Assistance Reference Centers. Rights. 


\section{INTRODUÇÃO}

Diversos países do mundo defrontam-se com uma nova perspectiva populacional: o envelhecimento da população mundial, um fenômeno recente. Uma população é considerada envelhecida quando a proporção de pessoas com 60 anos ou mais atinge $7 \%$ da população total e, ainda assim, apresenta tendências para o seu crescimento. Segundo a Organização das Nações Unidas (ONU, 2002), o número de pessoas com idade acima de 60 anos triplicará em 50 anos, totalizando cerca de dois bilhões. Os efeitos do envelhecimento da população já vêm sendo observados em todo o mundo, inclusive no Brasil. Os dados do Censo 2010 do Instituto Brasileiro de Geografia e Estatística (IBGE) projetam para o ano 2025 a população de idosos do Brasil superior a 16\%, o que colocará o Brasil em quinto lugar no ranking mundial de países com maior população de idosos. Conforme estimativas do IBGE, em 2060, o Brasil passará a ter 58,4 milhões de idosos, correspondendo a $26,7 \%$ do total da população. O país contabiliza hoje mais de 3,5 milhões de idosos com idade superior a 80 anos. Em 2060, esse público será de 19 milhões, o que corresponde a um crescimento equivalente a 27 vezes em relação a 1980, quando o país possuía menos de um milhão de pessoas nessa faixa etária: 684.789 de pessoas (IBGE, 2010).

O assunto que move o presente artigo objetiva tornar visíveis as lógicas e motivações presentes na violência de gênero praticadas contra pessoas envelhecidas, particularmente as mulheres idosas inseridas nos Centros de Referência da Assistência Social (CRAS) do município de Aracaju (SE), ampliar estudo anterior desenvolvido com pessoas idosas inseridas no Núcleo de Pesquisas e Ações da Terceira Idade (NUPATI) da Universidade Federal de Sergipe (UFS), e contribuir para a avaliação de políticas e programas relacionados ao atendimento de pessoas idosas.

Para Debert (2001), dentre os fatores que influenciaram no aumento da expectativa de vida dos últimos anos estão a diminuição da fecundidade nas últimas décadas, a redução da mortalidade infantil, melhorias no saneamento básico, controle de doenças, dentre outros. Essas mudanças estão diretamente atreladas às famílias, que levou a alterações nos seus papéis sociais, redução do número de filhos, migração rural-urbana, que modificam as funções tradicionais da família como educadora de crianças e de cuidadora dos mais velhos. Se, por um lado, o envelhecimento populacional e a longevidade são grandes vitórias em termos sociais e científicos, por outro acarretam 
desafios em termos econômicos, sociais e culturais. Anthony Giddens (1992) considera ilusório pensar que essas mudanças são acompanhadas de uma atitude mais tolerante em relação às idades. Entretanto, ao projeto reflexivo do eu - que Giddens considera estar em compasso com uma sociedade mais democrática - as mudanças devem ser associadas às novas concepções do corpo e as formas como elas recodificam a velhice.

As mudanças e os desafios a elas inerentes interferem em vários aspectos, como a violência. Nesse contexto, a violência continua sendo uma das maiores preocupações que a pessoa idosa pode vir a enfrentar no processo de envelhecimento. É necessário, desse modo, abordar os diferenciais de gênero, no processo de envelhecimento populacional como um fenômeno mundial, fazendo-se essencial o desenvolvimento sobre a questão, não apenas para denunciar, mas para reconhecer e identificar suas formas e propor maneiras de intervenção adequada para a proteção da vítima.

No caso da pessoa idosa, há dados que indicam o aumento de violência (IPEA, 2020), sendo necessário observar como se expressa na particularidade da mulher idosa. Pela Convenção de Belém do Pará, entende-se por violência contra as mulheres "[...] qualquer ação ou conduta baseada no gênero que cause morte, dano físico, sexual ou psicológico à mulher, tanto no âmbito público como privado." (OEA, 1994, n.p.). O fato de as mulheres viverem diferentes situações de violência ao longo das suas vidas traduz-se em um fim comum de experiência vital (subjetiva e social) que compartilhamos com outras congêneres. As violências patriarcais devem ser reconhecidas como um problema social que afeta a todos/as, deixando de ser pensado como um assunto que se limita à esfera vida privada.

Conforme especifica a Lei $n^{\circ} 10.741$ de $1^{\circ}$ de outubro de 2003, Estatuto do Idoso, é considerada idosa a pessoa com idade igual ou superior a 60 anos, para quem se regulam os direitos assegurados na legislação vigente (BRASIL, 2003). As relações entre terceira idade e outras idades, na sociedade atual, têm sido discutidas no que diz respeito à terminologia idoso, a partir do que se criam estereótipos e crenças sobre como as pessoas se referem aos demais nessa fase da vida. O uso de palavras para se referir às fases da vida é modificado com o passar do tempo e com as mudanças da sociedade. Velho, idoso, envelhescente, melhor idade, maior idade e terceira idade são termos que costumam ser utilizados para se referir à mesma fase da vida. As novas imagens do envelhecimento são, sem dúvida, expressões de um contexto marcado por mudanças culturais que redefinem o modo de construção das identidades. A concepção de velhice extrapola o aspecto meramente biológico e reflete também aspectos socioculturais e exige que a sua 
compreensão aborde a totalidade de aspectos que a circunda, inclusive as relações sociais de gênero a ela associadas.

Ao apontar a necessidade de evidenciar os mecanismos que suscitam socialmente a experiência de grupos diferentes, Scott (1999, p. 27) enfatiza que "não são os indivíduos que têm experiência, mas os sujeitos é que são constituídos através da experiência". A experiência, de acordo com essa definição, torna-se não a origem da nossa evidência autorizada (porque vista ou sentida) que fundamenta o conhecimento, mas sim aquilo que buscamos explicar, aquilo sobre o qual se produz conhecimento.

Nesse sentido, e destacando o perfil de mulheres idosas, há que se considerar que gênero dá conta da diversidade da condição/experiência feminina em sociedades distintas, no tempo e espaço, possibilita pensar as relações entre os sexos no plano das relações sociais de gênero (entre mulheres e homens, bem como entre mulheres e mulheres e entre homens e homens). O sujeito é constituído de gênero, classe, raça/etnia: é, portanto, múltiplo. Nega-se a existência do não sujeito em qualquer hipótese (SAFFIOTI, 1997).

De acordo com Sardenberg (1998) o conceito de gênero não substitui a categoria mulher, tampouco torna irrelevante pesquisas/reflexões sobre mulheres enquanto um grupo social discriminado. Ao contrário, permite que se pense essa categoria como uma construção social historicamente específica e como é legitimada a situação de discriminação, exploração e subordinação das mulheres. As divisões entre as idades são arbitrárias, logo, juventude e velhice não seriam apenas dados, mas construções sociais originárias da luta entre os jovens e os velhos. Assim sendo, as diferenças entre homens e mulheres são também construídas histórica e socialmente, percebidas especialmente nas relações de poder estabelecidas entre si. O estereótipo de gênero acaba legitimando essa forma de poder, da dominação masculina, naturalizando diferenças socialmente construídas, ou seja, o termo gênero refere-se a uma construção inteiramente social de ideias sobre papéis adequados a homens e mulheres. (BOURDIEU, 1983).

Segundo Beauvoir (1980, p. 343), enquanto o homem "[...] envelhece de maneira contínua [...]", a mulher, na maturidade, é "[...] bruscamente despojada de sua feminilidade". Assim, a autora reconhece que "[...] a história da mulher - pelo fato desta se encontrar ainda encerrada em suas funções de fêmea - depende muito mais que a do homem de seu destino fisiológico". As relações gênero e classe são dimensões fundamentais da vida social, estruturam as expectativas, conformam a ação social, são mutuamente articuladas e especialmente importantes na análise e explicação das diferentes trajetórias de vida percorridas socialmente por homens e mulheres. 
Dependendo da classe social ou dos arranjos familiares no qual se insere, ser idosa pode representar viver em condição de abandono material (mesmo quando aposentada, pois essa mulher pode ser explorada como auxiliar doméstica dos filhos) e de solidão afetiva (devido ao maior número de viúvas, divorciadas ou solteiras com filhos), ou até mesmo quando casadas, pois, muitas vezes, as trajetórias dos gêneros não foram construídas para convergir em companheirismo (BRITTO DA MOTTA, 2010).

Para Azevedo e Tavares (2014), na medida em que as feministas omitem das suas reflexões teóricas a situação das mulheres idosas e ainda ignoram a sua exclusão das políticas públicas destinadas às mulheres, torna-se evidente que há uma concordância com orientações tácitas, sustentadas em convenções que consideram a velhice como uma categoria social homogênea, sem sexo. Tais convenções tendem a desclassificar as idosas da condição de mulheres que sofrem as hierarquias e constrangimentos de gênero, inseridos em especificidades criadas pela situação de idade e geração, articuladas com a classe social, a raça/etnia dentre outros marcadores sociais de desigualdades. Na pesquisa e na própria militância feminista, há tentativas de trabalhar, na teoria, a importância da articulação da categoria gênero com algumas outras dimensões básicas das relações sociais, frequentemente ignoradas. Em sua maioria, os estudos limitam-se à raça/etnia e à classe social, por vezes, à orientação sexual. Isso não é suficiente, ignoram-se outras intersecções analíticas importantes, como a existente entre gênero e idade/geração (BRITTO DA MOTTA, 2010).

Com relação à violência, desde os anos 1990 já se discutia a definição de violência contra o idoso. Para Minayo (2005), a violência refere-se aos processos e relações sociais interpessoais, de grupos, de classes e de gênero, nos quais causam danos físico, mental ou moral. Podemos falar de mulheres na produção da violência de gênero como um fenômeno que pode ser identificado nas formas de opressão e dominação relacionadas aos elevados índices de episódios praticados contra mulheres, particularmente a violência doméstica, que não se restringe a qualquer caráter, seja pela classe social, raça/etnia, grau de escolaridade, religião, faixa etária e orientação sexual. Assim sendo, a violência de gênero decorre da própria forma pela qual se organizam socialmente as relações entre homens e mulheres.

Particularmente a pessoa idosa, frequentemente, encontra-se destituída de proteção tornando-se vulnerável à violência praticada pelos vários segmentos da sociedade. Esta situação contribui para que as idosas se sintam discriminadas e violadas nos seus direitos humanos fundamentais, gerando consequências em suas vidas, tanto para sua saúde física 
e mental, como para o seu convívio social. Conforme reflete Arendt (2001), os seres humanos não nascem iguais, mas se tornam iguais como membros de uma coletividade, em virtude de uma decisão conjunta que garante a toda esta coletividade igual. Para a autora, a igualdade resulta da organização humana, que, por meio da lei torna (ou deveria tornar), os homens iguais. Dessa forma, as diferenças deveriam ser igualadas por intermédio das instituições e, assim, a igualdade deveria ser garantida e ter espaço na esfera pública (já que a diferença tem lugar na esfera privada).

De acordo com Saffioti $(1997 ; 2001)$, a sociedade brasileira caracteriza-se por um alto índice de violência familiar que recai sempre sobre as mulheres, crianças ou velhos, o que deve ser considerado a fim de possibilitar a compreensão de sua rotinização. As mulheres de idade avançada enfrentam muitos desafios gerados por uma sociedade sexista e gerofóbica, pois, como ressalta Salgado (2002, p. 9) "[...] as crenças sexistas e gerofóbicas refletem a ênfase da sociedade na produtividade, no atrativo sexual e físico". Ainda conforme a autora, gerofobia é o termo que se usa para descrever os preconceitos e estereótipos em relação às pessoas idosas, fundados unicamente em sua idade.

As mulheres compõem a maioria da população mundial, são mais numerosas entre a população de idosos em todo o mundo, constituindo um processo conhecido como feminização da velhice, um aspecto ligado ao modo como a sociedade lida com o fenômeno do envelhecimento, aos papéis socialmente postos a homens e mulheres no decorrer da história humana. Tais aspectos oferecem elementos teóricos para compreender como homens e mulheres relacionam-se uns com os outros e, consequentemente, vivenciam a velhice.

Britto da Mota (2012) ressalta que o início do século XXI traz como definições no processo de envelhecimento, novos códigos e configurações que dão centralidade ao apoio das pessoas idosas, por exemplo, como central na família. Essas definições, no final do século passado amparavam-se na "crise" da família, que tinha no casamento a centralidade questionada principalmente pelos movimentos feministas, e que já apontava para referência ao papel de idosos(as) como provedores(as). Outros códigos também se fazem presentes na atualidade. Se, neste século, se reconhece em categorias como mulher, gay, trans ou queer, a sua importância nas configurações da sociedade, não se pode perder de vista que se trata de um processo derivado de lutas da década de 1970, período em que o conceito de mulher, nos espaços a ela destinados, e a opressão do seu corpo foram especialmente questionados - mesmo que de modo universal e essencialista compartilhamos com Moi (2017) e Fuss (2017), a ideia de que ainda é politicamente 
essencial para as feministas defenderem as mulheres na condição de mulheres, independentemente da condição etária.

Para Salgado (2002, p. 9), o preconceito com mulheres idosas, na sociedade atual, é perpetuado universalmente e, como sinaliza, essa mulher é “[...] universalmente maltratada e vista como uma carga. É parte de uma maioria invisível cujas necessidades emocionais, econômicas e físicas permanecem, em sua maioria, ignoradas". Elas são vistas de forma negativa, a maioria dos seus direitos fundamentais permanecem invisíveis, suas necessidades emocionais, econômicas e físicas, em grande parte, são negligenciadas, colocando-as em vulnerabilidade. Colaboram com o nível de escolaridade, menor qualificação profissional, menos anos completos de estudo em relação aos homens, o que contribui para que elas recebam salários inferiores.

A mulher idosa frequentemente encontra-se como a única provedora material da família e dos filhos adultos dependentes da única renda oriunda de sua aposentadoria. As famílias sofrem impactos de mudanças nos processos de trabalho na sociedade capitalista, formas de exclusão de trabalhadores do mercado de trabalho, acentuando diferenças salariais entre mulheres e homens que chegam a $23 \%$ conforme alerta da Organização das Nações Unidas (ONU, 2002). Neste contexto, não restam dúvidas de que a sociedade atual se depara com um segmento populacional que está aumentando e que, por sua vez, é vulnerável; entretanto, observa-se que a violência contra idosos guarda contornos próprios que devem ser analisados em suas especificidades. Deve-se ter como foco as construções sociais acerca da velhice e as expectativas de papéis sociais que a mulher deve desempenhar nessa etapa de vida. Essa nova dinâmica vem exigindo, não somente o debate, mas atenção especial, ações efetivas do poder público e da sociedade para aqueles que estão envelhecendo, considerando o atendimento às novas demandas decorrentes das alterações fisiológicas, psicológicas, cognitivas e sociais evidenciadas nessa fase da vida, além das violências recorrentes que lhes têm atingido nos espaços sociais e intrafamiliares.

O Estado brasileiro, ao longo dos últimos 32 anos, construiu alguns dispositivos legais de amparo à pessoa idosa, entre eles os que estão inscritos na Constituição Federal, constituindo diretrizes para a elaboração da Política Nacional de Saúde do Idoso, além do Estatuto do Idoso. Todavia, diante da realidade de violência parece que apenas a existência de dispositivos não é suficiente para o enfrentamento do problema. Como se percebe, atualmente no Brasil, existe amparo legal ao combate à violência contra o idoso, o que não existe é efetivação suficiente das medidas de prevenção por parte do Estado, nem respeito 
e abertura de visão por parte da sociedade, muito menos conscientização e mais amor por parte das famílias.

\section{METODOLOGIA}

As relações sociais de gênero caminham no sentido de refletir e documentar o lugar das diferenças, de documentar a experiência vivida pelos diferentes sujeitos sociais como possibilidade de abrir caminhos de reprodução social. Especificamente, a epistemologia feminista trouxe a subjetividade como forma de conhecimento, propôs uma nova relação entre teoria e prática, reconheceu o lugar da emoção, da subjetividade e do corpo no conhecimento, concebidos como práxis, conscientização e empoderamento individual e coletivo. (DENZIN; LINCOLN, 2006).

A pesquisa de caráter qualitativo constituiu uma parceria entre o Núcleo de Estudos e Pesquisas Interdisciplinares sobre a Mulher e Relações de Gênero. (NEPIMG) da Universidade Federal de Sergipe e o Conselho Municipal dos Direitos da Mulher de Aracaju (CMDM) e contemplou prioritariamente, os relatos de idosas integrantes dos CRAS ${ }^{1}$. Foram consultadas diferentes fontes de informação: como revisão da literatura pertinente; estatísticas desagregadas por sexo/idade/geração de institutos de pesquisa; inquéritos policiais de denúncia da Delegacia de Grupos Vulneráveis (DAGV), envolvendo denúncias em relação à violação dos direitos das mulheres idosas e dados do Disque 100 (BRASIL, 2020), que surgiu no ano de 2003, inicialmente com foco no atendimento de crianças e adolescentes vítimas de abuso sexual. Também foi consultado o Plano Nacional de Enfrentamento à Violência Contra a Pessoa Idosa; Política Nacional do Idoso (BRASIL, 1994) e o Estatuto do Idoso (BRASIL, 2003). A pesquisa ampliou os dados de estudo anterior, desenvolvido na UFS com idosos(as) do NUPATI.

O estudo priorizou as idosas dos CRAS, cadastradas no Serviço de Convivência e Fortalecimento de Vínculos (SCFV) da Secretaria Municipal da Família e Assistência Social (SEMFAS). Segundo o Ministério do Desenvolvimento Social (MDS), o SCFV é um serviço organizado e realizado com grupos que reúne um número significativo de pessoas idosas de modo a prevenir as situações de risco social, ampliar trocas culturais e de vivências,

${ }^{1}$ Após a aprovação do Projeto pelo Comitê de Ética em Pesquisa com Seres Humanos (CEP) da UFS, de acordo com a Resolução 466/2012 do Conselho Nacional de Saúde (CNS), que trata da pesquisa envolvendo seres humanos. 
desenvolver o sentimento de pertença e de identidade, fortalecer vínculos e incentivar a socialização e a convivência comunitária.

OS CRAS são equipamentos sociais vinculados à Política de Assistência Social, que se estrutura em dois níveis de serviços: Proteção Social Básica e Proteção Social Especial. Os serviços de proteção social básica são executados nos CRAS, que se constituem, para os(as) usuários(as) da política de assistência social, a porta de entrada para os serviços socioassistenciais. São equipamentos que devem localizar-se em áreas caracterizadas como de maior vulnerabilidade social e têm como objetivo a prevenção de situações que levem a rompimentos de vínculos familiares e comunitários.

Procurou-se caracterizar o perfil dos(as) idosos(as) que participam dos CRAS em Aracaju, observando-se a predominância de mulheres de renda baixa em situação de vulnerabilidade social, consideradas minoria em garantia dos direitos básicos por questões étnicas, de origem, por questões financeiras e por questões de gênero, classe, idade geração e sexualidade. Ironicamente, o que chamamos aqui de minorias são, quantitativamente, a maioria da população. As idosas recebiam benefícios assistenciais e complementares da SEMFAS, conforme cadastro do SCFV.

O acesso às idosas ocorreu com autorização da SEMFAS e das próprias idosas. Foi utilizada a técnica do Grupo Focal (GATTI, 2005) prevista para 12 sessões nos CRAS, entre o os meses de fevereiro e março de 2020. O acesso aos grupos compostos predominantemente por mulheres ocorreu nos seguintes locais e datas: CRAS Dr. Carlos Fernandes de Melo (04/02); CRAS Terezinha Meira (05/02); CRAS Maria José (10/02); CRAS Carlos Hardmam (11/02); CRAS Risoleta Neves (14/02); CRAS Porto Dantas (02/03); CRAS Enedina Bonfim dos Santos (03/03); CRAS Pedro Averan (04/03); CRAS Gonçalo Rolemberg (05/03); CRAS Risoleta Neves (09/03); CRAS Santa Maria (09/03). O $12^{\circ}$ CRAS seria o CRAS Madre Tereza, mas no dia da visita o grupo de idosos participou de outra atividade. O Grupo Focal permitiu a interação grupal e a discussão ampla sobre o tema específico da violência, utilizando-se dinâmicas de grupo como estímulo para fomentar e sustentar discussões, o intercâmbio de saberes e as experiências entre participantes, iniciando-se com perguntas genéricas, aprofundadas a seguir, direcionando para o foco do estudo. As falas foram gravadas, com permissão das pessoas participantes, e transcritas para fins de análise e interpretação. Para fins de garantia de sigilo, as participantes foram identificadas por letras do alfabeto.

Os grupos nos CRAS são constituídos, na sua maioria por mulheres idosas, porém já se inserem pessoas adultas no sentido de estimular a intergeracionalidade. Embora de 
maioria compostos por mulheres, há participação de homens em alguns grupos. O destaque para o relato de mulheres idosas deu-se no sentido de dar voz a um segmento ainda pouco estudado, como afirma Britto da Motta (2012, p. 23), que ressalta ser a violência contra pessoas idosas "uma temática relativamente pouco analisada, se comparada à atenção nesse sentido dada a outros segmentos geracionais".

Em virtude dos impactos gerados pelo fenômeno do envelhecimento populacional, sobretudo da feminização da velhice, faz-se necessário compreender esse processo e o seu significado em nossa sociedade, tendo como base a contribuição teórica de vários autores que teorizam sobre a questão do envelhecimento, as relações de gênero, feminização da velhice e desigualdades sociais, mas ir além, com a escuta de mulheres participantes de serviços públicos que devem protegê-las na sua condição de vulnerabilidade. Nesta direção considerou-se essencial retratar e investigar dimensões da violência, como formas de desigualdade, como um passo fundamental para enfrentar esse problema, constituindo um desafio moral as pessoas que rejeitam e hostilizam os idosos. Ao registrar suas expressões sobre a violência, marca-se um processo nem sempre reconhecido na sociedade, mas que se faz necessário nesse início de século, como sinalizam Britto da Motta (2012) e Salgado (2002).

\section{A VIOLÊNCIA NA EXPERIÊNCIA DAS MULHERES IDOSAS DOS CRAS}

No Estado de Sergipe ainda são escassos os estudos que abordam a questão do envelhecimento, velhice e violência em suas diversas dimensões. No Estado, a população de pessoas com 60 anos ou mais corresponde a 11,33\%, sendo 6,48\% composto por mulheres e 4,88\% composto por homens. Com relação aos dados do Disque 100, no ano de 2018 houve 645 ligações sobre violência com idosos no estado e em 2019 houve 379 ligações. Os principais tipos de violação foram: violência psicológica, seguido de negligência, violência física e abuso financeiro. Em relação ao agressor 55,40\% correspondia aos filhos enquanto $44,6 \%$ a algum conhecido, a vítima predominante era do sexo feminino correspondendo a $63,7 \%$ enquanto os homens correspondiam a 32,3\%. Com relação aos inquéritos oriundos de denúncias na DAGV nos anos de 2019 e 2020 (primeiro semestre), relativos à população idosa residente em Aracaju, verificou-se o perfil do agressor, do idoso e o tipo de violência cometida, aqui registrado. Sobre os casos em 2019 foram instaurados 114 inquéritos e em no primeiro semestre de 2020 houve o registro de 
77 denúncias. Desses inquéritos $56 \%$ caracterizam-se como crime de menor potencial, como ofensas verbais, ameaças, danos ou contravenções penais de perturbação do sossego; abuso financeiro, maus tratos e negligência. Em relação às principais ocorrências estão os crimes ocorridos no ambiente doméstico tendo as mulheres como as principais vítimas, correspondendo a $70 \%$ dos casos.

Os espaços de atendimento e acompanhamento das pessoas idosas, por meio da Política de Assistência Social, configuram-se um dos caminhos possíveis para o acesso a esse grupo. O público alvo do atendimento nos CRAS constitui-se de famílias, referenciadas, seus membros e indivíduos com necessidades decorrentes das expressões da questão social que os colocam em situação de vulnerabilidade, com demandas decorrentes da fome, baixa renda, drogadição, situação de risco pessoal ou estrutural .

Desses atendimentos, observam-se questões que permitem compreender a dimensão das relações intergeracionais em vários aspectos, dentre os quais aqueles expressos em violência intrafamiliar, conflitos com os filhos (crianças ou adolescentes) e com a comunidade. Ressalta-se que há um perfil dos(as) que demandam os serviços socioassistenciais, inclusive em razão da necessidade de informação e encaminhamento para o acesso ao Benefício da Prestação Continuada (BPC) e a inserção no Programa Bolsa Família, ou, ainda, pelo interesse na capacitação por meio de cursos profissionalizantes, além de orientação e informação em relação ao atendimento das políticas públicas.

Com base nos grupos focais, observou-se que os relatos das idosas dos CRAS de Aracaju informam que as práticas não são homogêneas e nem as formas de vivenciá-las no cotidiano. No que se refere à situação de violência, por exemplo, os principais episódios são praticados por filhos e conhecidos tendo as mulheres como as principais vítimas, o que corrobora estudos já desenvolvidos em nível nacional (MINAYO, 2005; 2016). Foram relatados: violência social, violência institucional, abuso psicológico, abuso físico ou maustratos, negligência, violência patrimonial, abandono e violência sexual.

Embora os estudos nacionais (MINAYO, 2016) indiquem que as pessoas idosas estão submetidas às diversas formas de violência, desde aquelas que causam mortalidade (as principais decorrentes de queda e de acidentes de transporte) como as que estão diretamente vinculadas às dimensões estrutural (que se fundamenta na organização da sociedade e da cultura), institucional (associada aos maus tratos infligidos no âmbito dos serviços) e familiar, as expressões sobre violência em espaço do CRAS nem sempre abordam além das dimensões estrutural e institucional. 
A violência social mais presente ocorre nos espaços públicos em experiências de exclusão social, é enfatizada por falta de respeito a pessoas idosas. Uma das participantes sinaliza: "Nós convivemos com a violência em todos os lugares onde vamos. Precisamos ser respeitados, e que as pessoas tenham mais consciência, pois qualquer coisa que falamos as pessoas já vêm com agressividade, com stress e com violência." (Participante "A"). Outra participante argumenta que "O respeito não existe pelos jovens... eu falo uma coisa e ouço tanta barbaridade, que prefiro ficar calada, não adianta falar." (Participante "B"). Segundo Dias et al (2018), os idosos são submetidos a uma visão estereotipada de que resta viver os seus dias de forma submissa, sem o direito de opinar. As mulheres idosas têm a sua autonomia ameaçada, e os padrões sociais construídos historicamente impõem um modo submisso e dependente de ser velha. Elas são desvalorizadas pelo fato de serem mulheres e velhas, também são as principais vítimas da violência. A fragilidade e dependência aparecem então como aspectos não somente da imagem que se produz dos idosos, mas também da imagem que se produz das mulheres no patriarcado.

A violência institucional é pontuada no atendimento profissional de idosas em instituições de saúde, mediante maus-tratos e negligências de funcionários. Nesse sentido, as idosas expressam que o atendimento, que deveria seguir o que determina a legislação quanto ao acesso ao direito, esbarra em situações de violência: "Nos postos de saúde, quando peço alguma informação, levo o maior coice, agora eu tenho é medo de pedir alguma informação", afirma a Participante "C". Minayo (2016, p. 441) enfatiza que "no nível das instituições de prestação de serviços, as de saúde, as de assistência e as de previdência são as campeãs de reclamações nos órgãos de proteção, como Defensoria, Ministério Público e delegacias de idosos". Esse argumento é reforçado pela Participante "D", ao ressaltar que "As pessoas que fazem o trabalho como profissional nos postos de saúde tratam a gente mal, principalmente os idosos, falta muita humanidade por parte dos profissionais, nos tratam muito mal. Primeiro que a gente já precisa ir de madrugada pegar uma ficha, ainda".

Sem dúvida alguma, a questão da saúde é muito importante, pois dela decorre o bem-estar e condição de vida de qualquer pessoa, porém os(as) idosos(as) são bastante negligenciados(as) neste aspecto, pois inexiste uma política social que dê o tratamento necessário aos idosos conforme prevê os Artigos 15 a 19 do Estatuto do Idoso. Via de regra, as pessoas idosas, nessa fase da vida em que necessitam de atenção, são largadas à própria sorte e consideradas um peso social. 
A violência psicológica na família é frequentemente praticada por pessoas próximas como maridos, filhos, conhecidos, ou por algum familiar:

A violência começa dentro de casa, não só com a violência física, mas também com palavras que doem. O homem quanto mais idoso fica, mais denigre a imagem da sua esposa, chamando-a de velha. A gente ouve coisas absurdas, não é só a violência física, tem palavras que doem mais que um tapa. (Participante "D").

Pensar a violência intrafamiliar requer perceber todas as nuanças que o processo de envelhecimento suscita, principalmente no tocante à condição da mulher. É preciso compreender que o lar é o espaço onde mulheres e crianças [assim como os velhos] correm maior risco. A negligencia é frequentemente praticada por agressores filhos(as), com expressou a Participante "E": "O meu filho não faz a janta, não me dá a alimentação correta, não dá os medicamentos, é um total descaso." As relações intergeracionais são um ponto de partida para o acompanhamento das mulheres idosas pelos equipamentos sociais, principalmente na saúde e na assistência social, para identificar situações de violência nem sempre abordada nas ações desenvolvidas. Nessas relações há que se considerar, como expressa a Participante "F", que "Os filhos não têm paciência de cuidar dos pais, quando cuidam é só pelo interesse no dinheiro, são poucos os filhos que sabem valorizar os pais que tem", ou que, como indicou a Participante "G", "Meu filho me ameaçou colocar no asilo e minha nora é muito bruta".

O uso de álcool ou de algum tipo de entorpecente pelo agressor, que mora com a vítima, aumenta o risco de maus-tratos. A vulnerabilidade que a mulher experimenta durante toda a sua vida parece potencializar-se na velhice, a maior expressão é a violência doméstica que tem o seu maior significado no machismo naturalizado historicamente pela relação entre homens e mulheres em um modelo de sociedade patriarcal. Minayo (2016, p. 443-444) ressalta:

A caracterização desta relação em grande parte dos estudos é coincidente: agressor e vítima vivem na mesma casa; filhos dependentes financeiramente dos pais de idade avançada; idosos e idosas dependentes dos filhos para a sobrevivência; abuso de álcool e drogas por parte dos familiares; ambiente de vínculos afetivos frouxos na família; isolamento social dos familiares e da pessoa idosa; agressividade do idoso e da idosa com os familiares; e história de violência na família.

Segundo Gondim (2016), o idoso torna-se uma vítima fácil, pois muitas vezes depende de seus familiares para os diversos cuidados, seja na questão da saúde, nas relações sociais, na dependência financeira ou simplesmente pelo afeto e convívio familiar. Percebe-se que viver com os filhos não é garantia de respeito, cuidado adequado e 
ausência de maus-tratos (DEBERT, 2001). A violência psicológica, de alguma maneira, mantém a mulher idosa na situação de dependência abusiva, aprisionando-a em sentimentos opostos e, muitas vezes, causando feridas profundas marcadas pela dor e pelo sofrimento, como expresso pela Participante "G", que relatou: "A família é a primeira a não aceitar o idoso, ameaçam colocar em asilos.". O conflito de interesses intergeracionais pode levar à prática da violência contra o idoso, na medida em que este é considerado um sujeito improdutivo, dependente e obsoleto, do ponto de vista cultural tornando-se um ser marginalizado e excluído (CASTRO, 2015).

A violência física também acontece no âmbito doméstico, praticada geralmente por algum familiar conforme exemplos relatados pelas participantes: "Passei muito tempo apanhando do meu marido, já tive que fugir de casa várias vezes, sofri demais, ele morreu faz uns dois anos e vivo muito melhor agora." (Participante "H"), ou, como registra a Participante "l", que "O meu marido me judiava muito, eu tive que sair fugida de casa, para ele não me matar, eu tenho várias cicatrizes no corpo por causa dele. Depois que ele morreu eu me senti melhor e vivo bem melhor atualmente”, ou ainda o que indica a Participante "J", que relatou "Já sofri muito com o meu marido, graças a Deus ele foi embora" e a Participante "K", ao ressaltar que "As mulheres hoje têm mais coragem... na minha época as mulheres sofriam porque tinham que aguentar tudo caladas. Eu mesma já apanhei muito do meu marido e não podia fazer nada." Sobre esses aspectos, Peixoto (2000) argumenta que a morte do cônjuge particularmente para a mulher idosa pode ser uma tragédia ou uma forma de libertação.

A violência patrimonial é também observada entre as participantes pelo uso ilegal/impróprio dos bens/ativos, abuso econômico não consentido de recursos financeiros e patrimoniais de idosos, consistindo na exploração, praticada por companheiros, filhos(as) e terceiros. Embora ocorra no âmbito familiar, nem sempre é algo revelado como próprio. Entre as participantes dos Grupos Focais, a violência patrimonial, quando apresentada, surge como situações observadas, na maioria, em contextos diversos de quem a expressou: "A filha pega o dinheiro da idosa, deixa ela em um quartinho com tudo sujo, não da alimentação, ameaça a mãe." (Participante "L" acerca de uma vizinha idosa) ou "Os filhos pegam os benefícios dos pais, os filhos que são usuários de drogas, ameaçam a mãe e ficam com todo o dinheiro." (Participante "M", sobre uma pessoa idosa conhecida). Mas há situações que ocorrem com as idosas participantes no grupo, como revela a Participante "N": "A minha irmã quer tomar a minha pensão, ela já me trancou em casa sozinha isolada 
em casa. Me bateu com um pau. Um dia jogou um balde de água quente em mim, me colocou para dormir em um colchão todo sujo."

Para se protegerem e não verem seus familiares serem punidos, por medo de serem castigados com a perda do acolhimento que por hora recebem, alguns tentam negar os fatos por nutrirem sentimento de afeto pelos seus agressores, outros por vergonha, além daqueles que sofrem maus-tratos tão velados que não se dão conta de que estão sendo em situação de violência. Por isso, as estatísticas sobre a incidência de violência referentes a abusos físico e emocional, menosprezos, abandonos, desatenções crime e ausência de direitos sofridos pela pessoa idosa são imprecisas. Dias et al. (2018) demostram que é nas relações intrafamiliares e no espaço de moradia que a violência de gênero contra os idosos acentua-se, partindo do entendimento de que sendo alvo de estereótipos, o idoso é visto como alguém descartável que não merece atenção e nem ser escutado. Tais atitudes negativas provavelmente surgem do medo que as gerações jovens têm do envelhecimento.

Outro aspecto que merece destaque é o estado civil; a maioria das mulheres idosas são viúvas e muitas são chefes de família. Silveira e Nader (2019) advertem que a violência contra mulheres idosas, particularmente, apresenta similaridades com a violência que é praticada em outras etapas da vida das mulheres, pois é uma violência de gênero, mas existem especificidades que precisam ser destacadas, como as questões relacionadas à velhice e às gerações. O idoso, muitas vezes, acredita que aquela violência seja normal, frequentemente por vergonha e para proteger a família não efetuam denúncias.

A violência nos espaços públicos da sociedade também é sobremaneira relatada nos transportes coletivos: "Quando tem idosos no ponto de ônibus eles não param", revela a Participante "O"; ou, como sinaliza a Participante "P"," A violência vem por parte dos motoristas, cobradores e até mesmo passageiros. No ônibus as pessoas jovens fingem não ver idosas para não dar lugar"; ou ainda, como reforçam a Participante "Q", que diz que "Quando estamos sozinhas nos pontos de ônibus os motoristas passam direto, fingem que não vê, ou quando param é na maior raiva" e a Participante "R", ao relatar que "Uma vez subi no ônibus e sentei no banco de trás porquê não tinha outro, antes de eu me sentar ele andou tão rápido que caí e bati a minha costela, passei vários dias com ela doendo." Importa ressaltar, como sinalizado anteriormente, que

Os acidentes de transporte constituem a segunda causa de mortes violentas em pessoas idosas, e os índices deste tipo de agravo têm crescido em todo o mundo. Dada à vulnerabilidade desta população, os acidentes requerem muito tempo para recuperação, diminuindo a possibilidade de sobrevivência. (MINAYO, 2016, p. 439). 
Ser velho é uma situação vivida em parte homogeneamente, e em parte diferencialmente, de acordo com o gênero e a classe social dos indivíduos em um grupo de idade ou geração. As idosas percebem a velhice de forma positiva e negativa. A velhice é percebida como a melhor fase na vida, possibilitando obter maior autonomia, participação social, realização de determinadas atividades, antes não concretizadas, em outras fases da vida, em virtude das responsabilidades com os filhos e atividades domésticas: "Eu vivo bem melhor agora, do que quando era mais jovem, sofri demais com meu marido e agora posso fazer o que eu quiser." (Participante "K"). "Agora eu posso fazer o que eu quiser, não preciso dar satisfação." (Participante “J"). A velhice também é vista com demissões de negatividade: "Eu pensava que era a idade da facilidade, mas não é bem assim. Eu passo por situações que eu nunca passei antes, eu estou sofrendo agora. Eu ouço muito palavrão calada. Tem muita falta de respeito". (Participante "S"). Nota-se que a velhice pode acarretar consequências que permitem inferir que as idosas estão em potencial risco social, com as limitações trazidas pela idade, o preconceito, as carências entre outros problemas (ALMEIDA et al., 2015).

Foi unânime o reconhecimento da importância do Serviço de Convivência e Fortalecimento de Vínculos, pois a participação no grupo muda completamente a vida dessas mulheres, proporcionando um espaço de lazer, socialização, aprendizagem e descontração, em que, através das suas atividades, consegue preencher, pelo menos por um momento, o vazio existencial que muitas mulheres idosas enfrentam, a etapa do ninho vazio, quando os filhos ou filhas saem de casa, um período em que muitas mulheres experimentam sentimentos de depressão e de perda. (SALGADO, 2002).

É obrigação da família, da comunidade, da sociedade e do Poder Público assegurar ao idoso, com absoluta prioridade, a efetivação do direito à vida, à saúde, à alimentação, à educação, à cultura, ao esporte, ao lazer, ao trabalho, à cidadania, à dignidade, ao respeito e à convivência comunitária, contudo, a realidade mostra-se bem diferente. A questão do desrespeito ao idoso no Brasil deve ser considerado uma patologia cultural, social e política. Em uma tentativa de corrigir e coibir os desmandos sociais e políticos e dar dignidade à pessoa idosa foi instituído o Estatuto do Idoso pela Lei 10.741 , de $1^{\circ}$ de outubro de 2003.

\section{CONCLUSÃO}

A feminização da violência é um fenômeno que se evidencia na sociedade e deve ser pensada para que se atente às formas de enfrentamento no tocante às especificidades 
da população idosa. Os estudos indicam, e a pesquisa nos CRAS apontou, a prevalência das mulheres idosas viúvas vítimas da violência social, violência institucional, abuso psicológico, abuso físico ou maus tratos, negligência, violência patrimonial, abandono e violência sexual.

O perfil do agressor e os tipos de violência praticados apresentam características mais comuns na sociedade: mora com a vítima; é financeiramente dependente; abusa de álcool e drogas; possui vínculos familiares rompidos; há pouca comunicação e afeto; isolamento social dos familiares da pessoa de idade avançada; história pregressa de violência na família; os cuidadores terem sido vítimas de violência doméstica; padecerem de depressão ou de qualquer tipo de sofrimento mental ou psiquiátrico. Particularmente a violência contra a mulher idosa apresenta-se como um fenômeno permeado por questões sociais, culturais, educacionais, econômicas e políticas.

O arcabouço normativo atual admite de forma consensual, que os cuidados com a pessoa idosa são de responsabilidade conjunta da família, da sociedade e do Estado; assim, revisita-se a centralidade da família, tendo o Estado como apoio. A violência doméstica e familiar contra pessoas idosas não deve ser pensada como uma questão exclusiva das famílias quanto aos cuidados de seus velhos de maneira adequada.

Os resultados questionam a necessidade de o Estado apresentar políticas de apoio, estendendo os limites da assistência com a implementação das ações que estão previstas no Estatuto do Idoso e em outros marcos normativos que associem e firmem um sistema de proteção social. Trata-se da criação e extensão de programas de assistência, como as "casas-lares" para idosos, centros de cuidados diurnos, centros de convivência, programas de internamento domiciliar estruturados pelo Sistema Único de Saúde (SUS), com melhor acessibilidade e atendimento, reconhecimento da reinserção do idoso no mercado de trabalho, entre outras providências, que facilitariam a sua vida e de seus familiares, diminuindo os conflitos, e, consequentemente, o risco da violência.

A particularidade da situação de violência contra a mulher idosa é algo que deve ser foco de ações nos equipamentos sociais da Política Assistência Social, de forma a incorporar nos serviços medidas de proteção às mulheres e prevenção à situação de violência. Espera-se com os resultados obtidos nesta pesquisa, sua apropriação pelas instituições executoras de políticas públicas voltadas para este segmento da população, de forma a possibilitar compreender seu papel para assegurar direitos à pessoa idosa, especialmente às mulheres idosas em situação de violência. Há violência contra a mulher idosa, e a particularidade desse fenômeno deve ser incorporada nas ações dos CRAS. 


\section{REFERÊNCIAS}

ALMEIDA, A. V; Mafra, S. C. T; Silva, E. P; KANSO, S. A Feminização da Velhice: em foco as características socioeconômicas, pessoais e familiares das idosas e o risco social. Textos \& Contextos. Porto Alegre, v. 14, n 1, pp. 115 - 131, jan./jun. 2015. Disponível em: <https://www.researchgate.net/publication/282460699_>. Acesso em: 20 set. 2019.

ARENDT, H. Condição humana. Rio de Janeiro: Forense Universitária, 2001.

AZEVEDO, E. L.; TAVARES, M. S. As DEAMS desconhecem sexo e gênero na velhice: reflexões sobre mais uma modalidade de violência contra as mulheres. REDOR PERSPECTIVAS FEMINISTAS DE GÊNERO: DESAFIOS NO CAMPO DA MILITÂNCIA E DAS PRÁTICAS, 18. 2014. Recife. Anais [...]. Recife: Universidade Federal Rural de Pernambuco - UFRPE. 2014, p. 522-536.

BEAUVOIR, S. Da maturidade à velhice. In: BEAUVOIR, S. O segundo sexo: a experiência vivida. 9. ed. Rio de Janeiro: Nova Fronteira, 1980. Volume 2.

BRASIL. Lei $n^{\circ}$ 8.842, de 1994. Lei da Política Nacional do Idoso. Dispõe sobre a política nacional do idoso, cria o Conselho Nacional do Idoso e dá outras providências. Diário Oficial da União, seção 1, Brasília, DF, ano CXXXII, nº 03, p. 77, 11 de janeiro de 2002, Página 77. Brasília, DF, 1994 PL 5710/1990.

BRASIL. Lei $n^{\circ} 10.741$, de 01 de outubro de 2003. Estatuto do Idoso - Lei do Idoso. Dispõe sobre o Estatuto do Idoso. Diário Oficial da União, seção 1 Brasília, DF, ano CXL, nº 192 de 03 de outubro de 2003, p. 1. PL 3561/1997.

BRASIL. Secretaria de Direitos Humanos da Presidência da República. Disque 100. 2020. Disponível em: <https://www.gov.br/mdh/pt-br/acesso-a-informacao/disque-100-1>. Acesso em: 10 jun. 2020.

BOURDIEU, P. A juventude é apenas uma palavra. Questão de sociologia. Rio de Janeiro: Marco Zero, 1983. p. 112-121.

BRITO DA MOTTA, A. O final da vida no século XXI. Mediações, Londrina, v. 17 n. 2, p. 925, jul./dez. 2012.

BRITTO DA MOTTA, A. Violência contra as mulheres idosas - questão de gênero ou de gerações? In: SEMINÁRIO POLÍTICAS SOCIAIS E CIDADANIA, III. 2010. Salvador. Anais eletrônicos [...]. Salvador: Universidade Católica de Salvador, 2010. Disponível em: <http://www.interativadesignba.com.br/III_SPSC/arquivos/sessao8/225.pdf > Acesso em: 11 maio, 2020.

CASTRO, M.L.D. A feminização da violência contra o idoso. 2015. 34 f. Dissertação (Especialista em Psicologia Jurídica) - Faculdade Integrada- AVM, Universidade Cândido Mendes, Rio de Janeiro, 2015.

DEBERT, G. G.. A família e as novas políticas sociais no contexto brasileiro. Interseções.

Revista de Estudos Interdisciplinares, UERJ, Rio de Janeiro, ano 3, n. 2, jul./dez. 2001. 
Disponível em: <www.e-publicacoes.uerj.br intersecoes issue> download" PDF>. Acesso em 11 mar.2020

DENZIN, N. K.; LINCOLN, Y. S. O planejamento da pesquisa qualitativa: teorias e abordagens. Porto Alegre: Bookman, Artmed, 2006.

DIAS, M. J. S. et al. Violência simbólica contra mulher idosa nas relações de gênero.

Revista Interdisciplinar em Cultura e Sociedade, São Luís, v. 4, nº especial, 2018.

FUSS, D. O "risco" da essência. In: BRANDÃO, Izabel et al. (Org.). Traduções da cultura: perspectivas críticas feministas (1970-2010). Tradução Ildney Cavalcanti e Amanda Prado. Florianópolis: EDUFAL, Editora da UFSC, 2017.

GATTI, B. A. Grupo focal na pesquisa em ciências sociais e humanas. Brasília: Liber Livro, 2005.

GIDDENS, A. As transformações da intimidade. São Paulo: Editora da UNESP, 1992.

GONDIM, L. V. C.. Violência Intrafamiliar Contra o Idoso: Uma Preocupação Social e Jurídica. In: ENCONTRO INTERNACIONAL DO CONSELHO NACIONAL DE PESQUISA E PÓS-GRADUAÇÃO EM DIREITO (CONPEDI), V. 2016. Montevideo. Anais eletrônicos [...]. Facultad de Derecho. Universidad de la República Montevideo - Uruguay, 2016. Disponível em: <http://www.mpce. mp.br/esmp/publicacoes/edi002 _2011/ artigos/04>. Acesso em: 03 maio 2020.

INSTITUTO BRASILEIRO DE GEOGRAFIA E ESTATÍSTICA (IBGE). Censo demográfico. 2010. Disponível em: https://censo2010.ibge.gov.br. Acesso em: 12 maio 2019.

INSTITUTO DE PESQUISA ECONÔMICA APLICADA (IPEA). Atlas da violência 2020. Disponível em https://www.ipea.gov.br/portal/images/stories/PDFs/relatorio institucional/200826 ri atlas da violencia.pdf. Acesso em 16 set. 2021.

MINAYO, M. C.. Violência contra o idoso: o avesso do respeito a experiência a sabedoria. 2. ed. Brasília: Secretaria Especial dos Direitos Humanos, 2005.

MINAYO, M. C.; ALMEIDA, L. C. C. Importância da Política Nacional do Idoso no enfrentamento da violência. In.: ALCÂNTARA, A. O.; CAMARANO, A. A.; GIACOMIN, K.C. (orgs.). Política nacional do idoso: velhas e novas questões. 2016. Disponível em http://repositorio.ipea.gov.br/handle/11058/7253Acesso em 10 ago. 2020.

MOI, T. Introdução: Quem tem medo de Virginia Woolf? Leituras feministas de Woolf. In: BRANDÃO, I. et al. (org.). Traduções da cultura: perspectivas críticas feministas (19702010). Tradução Izabel Brandão. Florianópolis: EDUFAL, Editora da UFSC. 2017.

ORGANIZAÇÃO DOS ESTADOS AMERICANOS (OEA). Convenção de Belém do Pará - Convenção Interamericana para Prevenir, Punir e Erradicar a Violência contra a Mulher. 1994. 
Envelhecimento. Plano aprovado na II Assembleia Mundial do Envelhecimento realizada de 8 a 12 de abril de 2002, em Madri. Brasília: Programa das Nações Unidas para o Desenvolvimento - PNUD e a Secretaria Especial dos Direitos Humanos. Secretaria Especial dos Direitos Humanos, 2013.

PEIXOTO, C. E. Avós e netos na França e no Brasil: a individualização das transmissões afetivas e materiais. In: CICCHELLI, V. (Org.) Família e Individualização. R.J.: FGV, 2000.

SAFFIOTI, H. I. O. Violência de gênero: o lugar da práxis na construção da subjetividade. Lutas sociais. Revista do Núcleo de Estudos de Ideologias e Lutas Sociais (NEILS).Programa de Estudos Pós-Graduados em Ciências Sociais - PUC, n. 2, 1997.

SAFFIOTI, H. I. B. Contribuições feministas para o estudo da violência de gênero. Cadernos Pagu (16) 2001. Disponível em:<www.pagu.unicamp.br>. Acesso em: 13 maio, 2020.

SALGADO, C. D.S. Mulher idosa: a feminização da velhice. Estudos interdisciplinares sobre o envelhecimento, Porto Alegre, v. 4, p. 7-19, 2002.

SARDENBERG, C. M. B. O enfoque de gênero: fundamentos teóricos e aspectos práticos. Salvador: Ed. NEIM/UFBA, 1998.

SCOTT, J. Experiência. In: SILVA, A. L.; LAGO, M. C. S.; RAMOS, T. R. O. (org.) Falas de gênero. Santa Catarina: Editora Mulheres, 1999, p. 21-55. Disponível em https://historiacultural.mpbnet.com.br/feminismo/Joan_Scoot-Experiencia.pdf. Acesso em 15 ago. 2020.

SILVEIRA, L.; NADER, M. B. Histórias de vida de mulheres idosas em situação de violência: uma perspectiva de gênero e de geração. In: SIMPÓSIO NACIONAL DE HISTÓRIA, 30. 15 a 19 de julho de 2019. Anais eletrônicos [...]. Recife: ANPUH - Brasil. Universidade Federal de Pernambuco. 2019.

\title{
NOTAS
}

\author{
Maria Helena Santana Cruz \\ Doutorado em Educação (UFBA) \\ Universidade Federal de Sergipe \\ Programa de Pós-Graduação em Serviço Social e Departamento de Serviço Social, São Cristóvão/SE, Brasil \\ helenacruz@uol.com.br
}

\section{개ttps://orcid.org/0000-0002-7794-278X}

\section{Vera Núbia Santos}

Doutorado em Serviço Social (PUC/SP)

Universidade Federal de Sergipe

Departamento de Serviço Social e Programa de Pós-Graduação em Serviço Social, São Cristóvão/SE, Brasil venus se@uol.com.br

\section{(1) https://orcid.org/0000-0002-9040-7140}

Endereço de correspondência do principal autor

Rua Dr. Osório de Araujo Ramos, n. 210. Praia 13 de julho / CEP 49020700 - Aracaju/SE - Brasil 


\section{AGRADECIMENTOS}

Bolsista do PIBIC Laíssa Eduarda da Silva Oliveira pela colaboração na coleta e transcrição dos dados obtidos nas sessões do grupo focal; Secretaria Municipal da Família e da Assistência Social de Aracaju; Centros de Referências da Assistência Social de Aracaju. Conselho Municipal dos Direitos da Mulher de Aracaju.

\section{CONTRIBUIÇÃO DE AUTORIA}

Concepção e elaboração do manuscrito: M. H. S. Cruz, V. N. Santos

Coleta de dados: M. H. S. Cruz, V. N. Santos

Análise de dados: M. H. S. Cruz, V. N. Santos

Discussão dos resultados: M. H. S. Cruz, V. N. Santos

Revisão e aprovação: M. H. S. Cruz, V. N. Santos

\section{CONJUNTO DE DADOS DE PESQUISA}

Escolha uma das opções e apague as demais.

1) O conjunto de dados que dá suporte aos resultados deste estudo não está disponível publicamente.

\section{FINANCIAMENTO}

Pesquisa desenvolvida com Bolsa de Iniciação Científica do CNPq. Projeto submetido ao Edital 02/2019 COPES/POSGRAP/UFS sob número PVC8026-2019, intitulado EXPRESSÕES DE VIOLÊNCIA DE GÊNERO: RELATOS ORAIS DE IDOSOS/AS EM ARACAJU, com resultado disponível em https://pesquisapos.ufs.br/conteudo/63784-resultado-final-da-producao-intelectual-e-de-aprovacao-deprojetos-e-planos-de-trabalho-pibic-2019-2020 .

\section{CONSENTIMENTO DE USO DE IMAGEM}

Não se aplica.

\section{APROVAÇÃO DE COMITÊ DE ÉTICA EM PESQUISA}

Pesquisa aprovada pelo Comitê de Ética, CAAE 87227818.9.0000.5546, Parecer: 3.528.523, de 23 de agosto de 2019.

\section{CONFLITO DE INTERESSES}

Não se aplica.

\section{LICENÇA DE USO}

Os autores cedem à Revista Internacional Interdisciplinar INTERthesis os direitos exclusivos de primeira publicação, com o trabalho simultaneamente licenciado sob a Licença Creative Commons Attribution (CC BY) 4.0 International. Estra licença permite que terceiros remixem, adaptem e criem a partir do trabalho publicado, atribuindo o devido crédito de autoria e publicação inicial neste periódico. Os autores têm autorização para assumir contratos adicionais separadamente, para distribuição não exclusiva da versão do trabalho publicada neste periódico (ex.: publicar em repositório institucional, em site pessoal, publicar uma tradução, ou como capítulo de livro), com reconhecimento de autoria e publicação inicial neste periódico.

\section{PUBLISHER}

Universidade Federal de Santa Catarina. Programa de Pós-graduação Interdisciplinar em Ciências Humanas. Publicação no Portal de Periódicos UFSC. As ideias expressadas neste artigo são de responsabilidade de seus autores, não representando, necessariamente, a opinião dos editores ou da universidade.

\section{EDITORES}

Javier Ignacio Vernal e Silmara Cimbalista

\section{HISTÓRICO}

Recebido em: 15-08.20 - Aprovado em: 12-09.21 - Publicado em: 11.10.21 